\title{
Review: \\ Fitoremidiasi Limbah Logam Berat dengan Tumbuhan Akar Wangi (Vetiveria zizanioides L)
}

\author{
Yuli Ambarwati ${ }^{*}$, Syaiful Bahri ${ }^{1}$ \\ ${ }^{1}$ Jurusan Kimia, Fakultas Matematika dan Ilmu Pengetahuan Alam \\ Universitas Lampung, \\ Bandar Lampung, Indonesia, 35145 \\ yuli.ambarwati@fmipa.unila.ac.id
}

\begin{tabular}{|l|}
\hline Artikel Info \\
Diterima \\
tanggal \\
05.10 .2018 \\
Disetujui \\
publikasi \\
tanggal \\
30.10.2018 \\
Kata kunci : \\
akar wangi, \\
fitoremediasi, \\
logam berat
\end{tabular}

\section{ABSTRAK}

Fitoremediasi adalah teknologi pembersihan, penghilangan atau pengurangan polutan berbahaya, seperti logam berat, pestisida, dan senyawa organik beracun dalam tanah atau air dengan menggunakan bantuan tanaman (hiperaccumulator plant). Tanaman akar wangi atau vetiver merupakan tanaman dari famili Gramineae (rumput-rumputan) yang masih satu famili dengan serai wangi (citronella) dan serai dapur (lemon grass). Kelebihan tanaman ini adalah kemampuannya untuk menyerap bahan bahan racun berbahaya (B3) dan logam berat yang mungkin terbawa dalam sampah dan meresap ke dalam tanah. Disamping itu akar dari tanaman ini memberikan bau aroma khas yang juga dapat dimanfaatkan untuk bahan baku industri aromaterapi (Kastaman dkk, 2007). Vetiver pun memiliki kemampuan untuk mengolah polutan dan pencemar air, misalnya limbah dari pabrik, lindi atau air dari pembuangan sampah, maupun air dari bisnis pencucian mobil yang banyak mengandung zat-zat kimia. Penggunaan akar wangi sebagai fitoremidiasi terhadap logam cadmium (Cd) telah berhasil dilakukan oleh Patandungan dkk., (2012). Data ini membuka peluang untuk fitoremidiasi logam berat yang lain seperti timbal $(\mathrm{Pb})$, merkuri (Hg), seng (Zn), Kromium (Cr) dan logam berat lain.

\section{ABSTRACT}

Phytoremediation is the technology of cleaning, removing or reducing harmful pollutants, such as heavy metals, pesticides, and toxic organic compounds in soil or water using plant help (hyperaccumulator plant). Vetiver is a plant from the family Gramineae (grasses) which is still a family with fragrant lemon grass (citronella) and lemon grass. The advantage of this plant is its ability to absorb hazardous toxic substances (B3) and heavy metals which may be carried in the trash and seep into the soil. Besides that, the roots of this plant provide a distinctive aroma that can also be used as raw material for the aromatherapy industry (Kastaman, 2007). Vetiver also has the ability to process pollutants and water pollutants, for example waste from factories, leachate or water from waste disposal, as well as water from car wash businesses that contain chemicals. The use of fragrant roots as phytoremediation against cadmium metal (Cd) has been successfully carried out by Patandungan et al. (2012). This data opens opportunities for phytoremidiation of other heavy metals such as lead $(\mathrm{Pb})$, mercury $(\mathrm{Hg})$, zinc (Zn), Chromium (Cr) and other heavy metals. 


\section{PENDAHULUAN}

Vetiver, yang di Indonesia dikenal sebagai akar wangi (Vetiveria zizanioides), adalah sejenis rumput-rumputan berukuran besar yang memiliki banyak keistimewaan. Di Indonesia rumput ajaib ini baru dimanfaatkan sebagai penghasil minyak atsiri melalui ekstraksi akar wangi, tetapi di mancanegara vetiver banyak dimanfaatkan untuk berbagai keperluan ekologis dan fitoremediasi (memperbaiki lingkungan dengan menggunakan tanaman) lahan dan air seperti rehabilitasi lahan bekas pertambangan, pencegah erosi lereng, penahan aberasi pantai, stabilisasi tebing, dan sebagainya melalui teknologi yang disebut Vetiver Grass Technology (VGT) atau Vetiver System (VS), sebuah teknologi yang sudah dikembangkan selama lebih dari 200 tahun di India (Wijayakusuma, 2007).

Vetiver adalah tumbuhan spesial yang telah berevolusi sehingga mampu tumbuh walau pada daerah yang beriklim ekstrim sekalipun, tumbuhan ini sangat toleran terhadap iklim termasuk tanah dengan $\mathrm{pH}$ yang asam dan juga pada tanah yang kekurangan unsur hara.

Vetiver yang merupakan tanaman dari famili Gramineae (rumput-rumputan) ini masih satu famili dengan serai wangi (citronella) dan serai dapur (lemon grass). Vetiver memiliki berbagai nama, di antaranya khus khus, panni, valo di India, faeg di Laos dan Thailand, dan kusu-kusu, rumput wangi di Malaysia. Sementara di Indonesia sendiri, vetiver lebih dikenal dengan nama akar wangi, usar, ataupun larasetu. Vetiver dikenal sebagai rumput ajaib (miracle grass). Dikatakan sebagai miracle grass tentu bukan tanpa alasan. Rumput ini telah lebih dari 200 tahun digunakan petani di India sebagai pagar tanaman permanen. Selain itu, sejak 50 tahun terakhir, tumbuhan ini juga telah digunakan oleh pabrik gula sebagai pengukur konservasi lahan di wilayah-wilayah terpencil di dunia. Beberapa tahun terakhir rumput ini telah digunakan sebagai metode vegetatif konservasi alam dan air, rehabilitasi area yang rusak secara ekologis, seperti terkena bencana alam, maupun pencemaran.

Beberapa hasil penelitian menunjukkan bahwa kandungan logam berbahaya, pestisida, dan senyawa organik tertentu di dalam tanah dan air, terutama di kota besar dan kawasan industri, telah melampaui ambang batas dan cenderung menuju ke tingkat membahayakan. Oleh karena itu, dipacu oleh akibat kebocoran reaktor nuklir di Chernobyl - Rusia pada tahun 1986, beberapa peneliti Amerika dan Ukraina telah melakukan penelitian terhadap kemampuan tanaman jenis Indian mustard untuk meminimalkan kandungan unsur cesium dan stronsium 
dalam tanah yang telah terpapar oleh senyawa radioaktif. Sedangkan di Iowa - AS, para peneliti mencoba pohon poplar untuk menurunkan kandungan senyawa pestisida jenis atrazine yang terpapar di dalam tanah dan air tanah.

Penghilangan senyawa atrazine serta unsur radioaktif sangat penting karena kedua jenis senyawa itu merupakan senyawa karsinogenik. Beberapa tahun yang lampau beberapa peneliti Indonesia juga melakukan penelitian dan pengukuran daya penurun kandungan logam berat dan unsur radioaktif dengan menggunakan tanaman enceng gondok (Hidayati dkk., 2006). Namun dari studi literatur yang dilakukan oleh penulis menunjukkan bahwa peneliti Indonesia masih sedikit yang menggunakan vetiver sebagai obyek penelitiannya. Diantara yang sedikit tersebut adalah apa yang dilakukan oleh Patandungan dkk., (2012) tentang penggunaan akar wangi sebagai fitoremidiasi terhadap logam cadmium (Cd) di lahan Tempat Pembuangan Akhir (TPA) Tamangapa Antang Makassar. Untuk itu pada makalah ini penulis mencoba untuk melakukan studi literatur sabagai bahan awal untuk melakukan penelitian terkait dengan kemampuan vetiver dalam menyerap logam berat.

\section{Tanaman akar wangi (Vetiveria zizanioides)}

Vetiveria zizanioides merupakan salah satu spesies vetiver yang sangat penting dan dominan baik secara ekonomi maupun untuk konservasi lingkungan. Fakta menunjukkan bahwa minyak akar wangi (essential oil) telah digunakan oleh industri minyak wangi/parfum, industri farmasi sebagai bahan obat dan industri pertanian sebagai bahan insektisida nabati. Vetiver berasal dari kingdom Plantae, Orde Poales, family Graminae (Poaceae), subfamily Panicoideae, Genus Chrysopogon dan spesies Chrysopogon zizanioides atau Vetiveria zizanioides (http://www.vetiver.org). Vetiveria zizanioides merupakan rumput yang tinggi, kokoh, berumur tahunan, akarnya wangi, daun yang tipis dan panjang dengan sistem akar serabut yang melimpah, dan komplek (Chomchalow, 2001). Tumbuhan ini juga merupakan alternatif murah guna menahan erosi tanah. Akarnya telah dimanfaatkan oleh masyarakat di Asia sebagai pewangi, bahan anyaman tenun dan bahan kerajinan yang lain. Tumbuhan ini juga mengandung bahan aktif yang digunakan sebagai obat tradisional dan pestisida nabati (Chomchalow, 2001). Tinggi puncak tegaknya biasanya di atas 2 meter dan diatas 2,5 meter dengan bunganya. Vetiver memiliki bunga namun tidak menghasilkan biji atau buah (Gambar 1 a). Sistem perakarannya 
dapat mencapai panjang 5 meter pada kedalaman tanah dalam masa pertumbuhan 18 bulan (Gambar 1b). Akar dari beberapa spesies menghasilkan minyak esensial yang telah dipergunakan oleh masyarakat sejak beberapa abad yang lalu. Akarnya dapat tumbuh mencapai kedalaman 3-5 m sehingga kemampuan akarnya dalam mengikat tanah sangatlah kuat. Setiap akar vetiver memiliki kemampuan yang setara dengan 1/6 kekuatan baja dengan diameter yang sama yaitu mencapai 75 megapaskal (Yulistyne, 2008). Akar vetiver tumbuh lurus ke bawah tidak sama pada tumbuhan lainnya yang akarnya tumbuh menyamping. Karena itulah vetiver tidak akan mengganggu atau menjadi saingan untuk memperoleh makanan dengan tanaman lainnya. Selain itu, akar vetiver menyebar luas di dalam tanah dengan panjang akar yang mencapai 3-5 m ini sangat membantu menstabilkan tanah. Dengan akarnya yang panjang menghunjam ke dalam tanah, vetiver dapat dijadikan alternatif pengendalian longsor yang cukup murah.
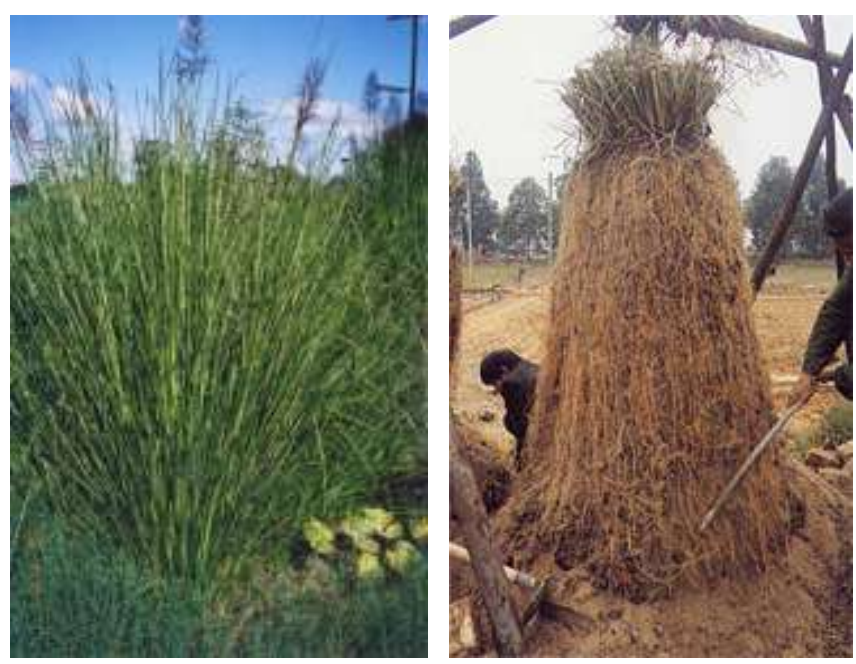

Gambar 1 a) Vetiveria zizanioides b) sistem perakaran dari Vetiveria zizanioides Sumber: http://www.vetiver.org

Untuk mendukung sanitasi lingkungan terutama di areal tempat pembuangan akhir sampah (TPA) tanaman akar wangi dapat ditanam disekitar areal bangunan. Kelebihan tanaman ini adalah kemampuannya untuk menyerap bahan bahan racun berbahaya (B3) yang mungkin terbawa dalam sampah dan menyerap ke dalam tanah. Disamping itu akar dari tanaman ini memberikan bau aroma khas yang juga dapat dimanfaatkan untuk bahan baku aromaterapi (Kastaman dkk, 2007). 


\section{Pencemaran Logam Berat}

Dalam beberapa tahun terakhir ini, bahaya yang muncul akibat kontaminasi logam berat di lingkungan tanah dan perairan adalah merupakan isu lingkungan yang sangat menonjol. Permasalahan pada lingkungan tanah terkontaminasi logam berat adalah tidak mudah untuk ditangani dengan cepat, karena melibatkan masyarakat yang ada di sekitarnya. Limbah yang dihasilkan dalam bentuk padat mungkin tidak berdampak luas, tetapi bila buangan dalam 3 bentuk limbah cair atau menguap berpengaruh lebih luas, karena penyebarannya dapat melalui air atau atmosfer (udara), sehingga bahaya kontaminasinya tidak mudah untuk diatasi. Sebagai contoh : di daerah bekas pertambangan emas di Teluk Buyat - Minahasa, walaupun keracunan $\mathrm{Hg}^{+}$terhadap masyarakat di sekitar daerah pertambangan masih diragukan, namun limbah $\mathrm{Hg}^{+}$ tetap merupakan toksik bagi ikan di perairan, dan manusia yang memakan ikan tercemar. Di sisi lain, logam-logam tersebut juga mempunyai peranan penting dalam proses kehidupan mikroorganisme. Beberapa logam-logam seperti : $\mathrm{Ca}, \mathrm{Co}, \mathrm{Cr}, \mathrm{Cu}, \mathrm{Fe}, \mathrm{K}, \mathrm{Mg}, \mathrm{Mn}, \mathrm{Na}, \mathrm{Ni}$, dan $\mathrm{Zn}$ adalah hara esensial dan berperan dalam proses redoks untuk menstabilkan molekul melalui interaksi elektrostatik. Namun ada beberapa logam yang tidak mempunyai peranan bioloigi, seperti : Ag, $\mathrm{Al}, \mathrm{Cd}, \mathrm{Au}, \mathrm{Pb}$, dan $\mathrm{Hg}$, karena bukan merupakan hara esensial (nonesensial), tetapi racun (toksik) bagi mikroorganisme. Logam-logam non-esensial ini dapat pula menggantikan posisi logam esensial yang terjerap dalam kompleks koloid atau melalui interaksi ligan. Bila kondisi ini terjadi, dapat merugikan mikroorganisme maupun tumbuhan yang menyerap unsur hara nonesensial tersebut (Taberima, 2004).

\section{Sumber-sumber logam berat}

Sumber-sumber logam berat dapat berasal dari hasil pelapukan batuan mineral dan antropogenik. Mineral dalam batuan merupakan mineral utama (mineral primer) dalam tanah sebagai akibat melapuknya batuan dan membetuk tanah. Mineral-mineral tersebut akan melapuk dan melepaskan unsur-unsur yang dikandungnya, sebagian merupakan hara bagi tanaman, sebagian tercuci dari tanah bersama air perkolasi atau erosi, dan sebagiannya lagi bereaksi membentuk mineral sekunder. Pelapukan akan berjalan terus, sehingga pada tanah-tanah dengan tingkat pelapukan lanjut (Ultisol, Oxisol) hanya tertinggal mineral sukar lapuk (kuarsa) dan mineral sekunder seperti : oksida besi (hematite, goetit) dan oksida Al (gibsit). Pelapukan adalah 
proses penghancuran fisik dan kimia dari batuan, karena mineral-mineral dalam batuan tersebut tidak berada dalam keseimbangan dengan suhu, tekanan, dan kelembaban yang ada. Pelapukan mineral primer diawali dengan adanya penurunan suhu. Mineral primer yang paling mudah melapuk adalah golongan Nesosilikat, seperti : olivin, diikuti piroksin, amfibol, biotit, dan seterusnya sebagaimana dikemukakan dalam seri reaksi Bowen (Hardjowigeno, 1993 dalam Taberima, 2004). Mineral-mineral tersebut adalah mineral kelam yang kaya unsur $\mathrm{Mg}$ dan $\mathrm{Fe}$ yang berasal dari batuan basalt atau ultra basalt. Dari setiap jenis mineral mudah lapuk akan dihasilkan hara-hara yang di dalamnya terkandung juga unsur-unsur logam berat dalam bentuk hara utama maupun hara minor. Proses pelapukan ini menghasilkan kadar logam berat yang tentunya berbeda dan tergantung dari bahan induknya, juga didukung oleh proses vulkanik yang sangat berperan dalam menghasilkan jenis batuan dan mineral.

Sumber logam berat yang berasal dari aktivitas manusia adalah logam berat yang dihasilkan melalui limbah dari suatu industri atau penambangan. Aktivitas manusia terhadap peningkatan pergerakan, perpindahan, dan akumulasi logam berat menyebabkan logam berat masuk ke atmosfir, tanah, atau ekosistem perairan melebihi kemampuan alami ekosistem tersebut untuk memprosesnya. Aktivitas industri menyebabkan peningkatan jumlah logam berat beracun (toksik) dan radionuclide yang diemisi ke biosfer, sehingga mempunyai indikasi potensi berbahaya bagi suatu ekosistem (Gazso, 2001 dalam Taberima, 2004). Kehadiran logam berat secara berlebihan dapat menyebabkan polusi pada air bawah tanah, toksik pada tanaman, dan pengaruh merugikan bagi jaringan tanaman atau mikroorganisme tanah (California State Water Resources Control Board, 2000).

Logam berat yang dilimpahkan ke perairan, baik di sungai ataupun laut akan dipindahkan dari badan airnya melalui beberapa proses yaitu : pengendapan, adsorbsi dan absorbsi oleh organisme perairan. Logam berat mempunyai sifat yang mudah mengikat bahan organik dan mengendap di dasar perairan dan bersatu dengan sedimen sehingga kadar logam berat dalam sedimen lebih tinggi dibandingkan dalam air.Logam berat mempunyai sifat yang mudah mengikat dan mengendap di dasar perairan dan bersatu dengan sedimen, oleh karena itu kadar logam berat dalam sedimen lebih tinggi dibandingkan dalam air (Harahap, 1991). 
Konsentrasi logam berat pada sedimen tergantung pada beberapa faktor yang berinteraksi. Faktor-faktor tersebut adalah :

1. Sumber dari mineral sedimen antara sumber alami atau hasil aktifitas manusia.

2. Melalui partikel pada lapisan permukaan atau lapisan dasar sedimen.

3. Melalui partikel yang terbawa sampai ke lapisan dasar.

4. Melalui penyerapan dari logam berat terlarut dari air yang bersentuhan.

\section{Pengolahan Limbah Logam Berat}

Pencarian teknologi yang lebih efektif dan ekonomis untuk pengolahan ion logam berat terutama dari kegiatan industri seperti electroplating, industri hidrometalurgi dan industri smelting mulai banyak dilakukan, salah satunya adalah dengan metode biosorpsi.

Banyak metode yang telah dikembangkan untuk menurukan kadar logam berat dari badan perairan, misalnya dengan teknik presipitasi, evaporasi, elektrokimia dan pemakaian resin. Metode tersebut dianggap kurang efektif karena membutuhkan biaya yang cukup tinggi dalam pengoperasiannya.

Dewasa ini telah banyak pula dikembangkan teknologi aplikasi adsorpsi, yakni menggunakan bahan biomaterial untuk menurunkan kadar logam berat dari badan air (biosorpsi), seperti sekam padi (Munaf, 1997 dalam Marganof 2003), daun lumut yang digunakan dalam proses adsorpsi kromium dari air limbah (Sharma DC,1994 dalam Banat F dkk, 2000), lumut sphagnum (sphagnum peat moss) untuk adsorbsi tembaga, begitu juga dari bahan non biomaterial seperti perlit, tanah gambut dan lumpur aktif (Marganof, 2003).

Penelitian saat ini berkembang untuk membersihkan logam berat menggunakan tanaman hidup sebagai akumulator logam berat dan juga menggunakan mikroorganisme. Fitotoremediasi adalah teknologi untuk membersihkan daerah yang terkontaminasi logam berat dengan harga murah. Metode ini diterapkan pada pencemaran lingkungan yang paling parah seperti kontaminasi arsen pada lahan bekas instalasi senjata kimia (Feller 2000) dan memiliki keuntungan estetis. Teknologi ini paling efisien untuk tanah yang terkontaminasi dekat akar tanaman dengan kedalaman 1 meter (Wilde. 2005.; Khan, 2000). Tanaman adalah komponen penting dari ekosistem karena tanaman membawa unsur-unsur dari lingkungan abiotik ke lingkungan biotik (Chojnacka et al., 2005). Tanaman lebih tahan dibandingkan kebanyakan 
mikroorganisme pada konsentrasi kontaminan tinggi, tanaman juga menyerap dan mengurangi toksisitas kontaminan jauh lebih cepat (Schnoor et al., 2005).

Dari beberapa metode di atas masih sangat sedikit informasi tentang bagaimana mekanisme penyerapan logam berat oleh vetiver. Namun demikian diketahui bahwa vetiver mempunyai daya adaptasi pertumbuhan yang sangat luas. Tanaman ini dapat tumbuh baik di lingkungan yang tidak menguntungkan termasuk pada lahan berat yang : (1) masam, mengandung mangan dan alumunium; (2) bersalinitas tinggi dan mengandung banyak natrium; (3) mengandung logam berat seperti $\mathrm{Ar}, \mathrm{Cd}, \mathrm{Co}, \mathrm{Cr}, \mathrm{Pb}, \mathrm{Hg}, \mathrm{Ni}$, Se, dan $\mathrm{Zn}$ (Wijayakusuma, 2007).

\section{KESIMPULAN}

Dari uraian yang telah dipaparkan di atas maka dapat disimpulkan bahwa akar wangi (vetiver) mempunyai potensi besar dalam pengolahan limbah logam berat.

Studi ini merupakan penelusuran literatur sehingga diperlukan penelitian secara eksperimen untuk membuktikan secara ilmiah tentang potensi akar wangi sebagai pengolah limbah logam berat.

\section{DAFTAR PUSTAKA}

Banat F., Al-Asheh S., 2000, "Biosorption of Phenol by Chicken Feather", Environmental Engineering and policy, 2:85-90

California State Water Resources Control Board, 2000, Risks and Benefits.

Chomchalow, N.,2001, The Utilization of Vetiver as Medicinal and Aromatic Plants with Special Reference to Thailand. PRVN Tech.Bull. No. 2001/1, ORDPB, Bangkok.

Chojnacka K., Chojnacki A., Gorecka H., Gorecki H., 2005, "Bioavailability of heavy metals from polluted soils to plants", Science of the Total Environment. Vol. 337. P. 175-182

Feller AK.,2000, "Phytoremediation of soils and waters contaminated with arsenicals from former chemical warfare installations". Di dalam: Wise DL, Trantolo DJ, Cichon EJ, Inyang HI, Stottmeister U (ed). Bioremediation of Cotaminated Soils. New York: Marcek Dekker Inc. hlm 771-786. 
Hidayati, Nuril.; Fauzia Syarif, dan Titi Juhaeti, 2006, "Potensi Centrocema pubescence, Calopogonium mucunoides, dan Micania cordata dalam Membersihkan Logam Kontaminan pada Limbah Penambangan Emas". Biodiversitas. Volume 1 No. 7 Hal. 46. http://www.vetiver.org

Harahap, S., 1991, "Tingkat Pencemaran Air Kali Cakung Ditinjau dari Sifat Fisika-Kimia Khususnya Logam Berat dan Keanekaragaman Jenis Hewan Benthos Makro", IPB , Bandung.

Kastaman, Roni dan Kramadibrata, Ade Moetangad, 2007, "Rancangan Teknis Operasional Sistem Pengelolaan Reaktor Sampah Terpadu (SILARSATU) Berbasis masyarakat”. Divisi Pengembangan Informasi dan Teknologi Tepat Guna, Universitas Padjadjaran. Bandung. 171 halaman.

Khan AG, Kuek C, Chaudhry, TM, Khoo CS, Hayes, WJ., 2000, "Role of plants, mycorrhizae and phytochelators in heavy metal contaminated land remediation", Chemosphere 41:197-207.

Marganof, 2003, "Potensi Limbah Udang sebagai Penyerap Logam Berat (Timbal, Kadmium, dan Tembaga) di Perairan”, Makalah Pribadi Pengantar ke Falsafah Sains PPS/S3 IPB. Bogor. 12 halaman.

Patandungan, Alfia., Syamsidar HS., Aisyah., 2012, "Fitoremidiasi Tanaman Akar Wangi (Vetiver zizanoides) Terhadap Tanah Tercemar Logam Kadmium (Cd) Pada Lahan TPA Tamangapa Antang Makassar.

Schnoor J. L., Licht L. A., McCutcheon S. C., Wolfe N. L.,Carriera L. H., 2005, "Phytoremediation: an emerging technology for contaminated sites", http://www.engg.ksu.edu/HSRC/Abstracts/schnoor.html (2007 01 12).

Taberima, Sartji., 2004, "Peranan Mikroorganisme dalam mengurangi efek toksik pada tanah terkontaminasi logam berat”. Makalah Falsafah Sains. PPS/S3 IPB. Bogor. 21 halaman.

Wijayakusuma, Rully, 2007, "Stabilisasi Lahan dan Fitoremidiasi dengan Vetiver Sistem." Artikel Green Design Seminar, Prigen, Pasuruan Jawa Timur. 16 halaman.

Wilde E. W., Brigmon R. L., Dunn D. L., Heitkamp M. A., Dagnan D. C., 2005, "Phytoextraction of lead from firing range soil by Vetiver grass", Chemosphere. Vol. 61. P. 1451-1457

Yulistyne, 2008, “Akar Vetiver 1/6 Kekuatan Baja”. Makalah Sains. Pikiran Rakyat. Bandung. Jawa Barat., J. Membr. Sci., 41, 197 - 209. 